\title{
PESQUISA E TRABALHO PROFISSIONAL COMO ESPAÇOS E PROCESSOS DE HUMANIZAÇÃO E DE COMUNHÃO CRIADORA
}

\author{
Maria Waldenez de Oliveira*
}

RESUMO: Neste artigo desenvolvo algumas compreensões sobre práticas de pesquisa e trabalho profissional com comunidades populares. Entendendo que nessas práticas sociais podem ser gerados processos de humanização, propõe-se que elas se constituam em espaços de construção de intersubjetividades e de elaboração do mundo em comunhão, em colaboração-participação, em comunidades de trabalho nas quais nos comprometemos com a construção de uma sociedade mais justa. A convivência é apresentada como vital nesse processo dialógico; para garanti-la, torna-se fundamental prevê-la metodologicamente. Conclui-se que a comunhão e a convivência, quando pautadas no diálogo e no compromisso mútuo entre profissionais e comunidades, propiciam a apreensão das diversas visões de mundo, ampliação conjunta da compreensão de si e do mundo e a construção de propostas transformadoras mais próximas da concretude da vida das pessoas.

Palavras-chave: Educação popular e saúde. Diálogo. Convivência. Participação.

\section{RESEARCH AND PROFESSIONAL WORK AS SOCIAL SPACES AND HUMANIZATION AND CREATIVE COMMUNION PROCESSES}

ABSTRACT: This paper presents some results derived from practices of research and professional work with popular communities. Understanding that such social practices may generate humanizing processes, it proposes that they constitute spaces were intersubjectivities

Doutora em Educação e professora do Centro de Educação e Ciências Humanas da Universidade Federal de São Carlos (ufSCAR).E-mail:dmwo@ufscar.br 
Pesquisa e trabalho profissional como espaços e processos de humanização...

are built and world in communion are designed in a contributionparticipation within work communities committed to build a fairer society. Coexistence is introduced as vital in this dialogical process; to guarantee it, it is crucial to foresee it methodologically. Conclusions show that, when grounded in dialogue and mutual commitment between professional workers and communities, communion and coexistence allow to seize different world views, widen the understanding of oneself and the world and present transforming proposals closer to the concrete life of people.

Key words: Popular education and health. Dialogue. Coexistence. Participation.

\section{Apresentação}

E ste artigo apresenta algumas experiências e reflexões sobre diálogo entre conhecimentos produzidos na perspectiva de grupos acadêmicos e aqueles produzidos na perspectiva de grupos populares. Em nossos trabalhos de pesquisa, ensino e extensão, buscamos estabelecer uma aproximação mais efetiva com grupos populares, tais como: jovens moradores de periferia, trabalhadoras do sexo, praticantes de medicinas populares, entre outros. No trabalho conjunto buscamos viver e construir, cotidianamente, ações dialógicas no enfrentamento das desigualdades sociais e na recriação humanizadora do mundo. Forjamos espaços de sobrevivência, resistência, espaços de educação, de construção coletiva ou individual de conhecimentos e projetos. Buscamos ampliar a compreensão crítica da realidade, seja por parte do grupo acadêmico, seja por parte dos demais grupos, num processo contínuo de formação de educadores para o fortalecimento de comunidades. Esses trabalhos nos trazem elementos para se pensar a educação escolar, particularmente no âmbito da formação de pesquisadores, professores e profissionais de saúde, onde atuo como docente de universidade pública. ${ }^{1}$

É neste contexto de construção de conhecimentos, de estudos, experiências e debates conjuntos que escrevo este artigo, numa leitura de como pessoas e grupos constroem e mantêm práticas humanizantes e apontam lições para nossos trabalhos de Educação Popular e Saúde. Busca-se contribuir com a construção de práticas educativas dialógicas nos serviços de saúde, nos centros de formação profissional e de pesquisadores, entre outros espaços. 


\section{Situando-se na América Latina}

A história da América Latina é marcada por práticas sociais desumanizantes, nas quais se aprende o silenciamento, a orfandade cultural (Dussel, s/d), mas também a sobrevivência, a tradição, a resistência, pois:

O escravismo e o colonialismo não subordinaram tudo. A estrutura de castas não dissolveu nem a originalidade, nem a força das culturas e modos de vida dos guaranis, maias, astecas e outras nações indígenas. $\mathrm{O}$ mesmo se pode dizer dos membros de nações africanas transportados para o Novo Mundo como escravos. (Ianni, 1993, p. 52)

No processo de reconquistar sua humanidade negada e usurpada pelos colonizadores e escravistas, os povos latino-americanos construíram espaços sociais de luta diária pela vida e pela dignidade, onde redescobriam e redescobrem sua condição humana. Essa construção nos ajuda a pensar práticas antagônicas àquelas que insistem em atribuir a algumas pessoas valores "mais" humanos que a outras, por sua vez entendidas como incapazes por natureza, imorais, sem conhecimento, sem escolaridade; enfim, como pessoas sem cultura. Práticas desumanizantes ainda permanecem em nossa realidade, gritantes para alguns e invisíveis para outros. São heranças de um pensamento colonizador que promoveu a exploração e morte de diversos povos da América Latina. No processo histórico de suas lutas, esses povos vêm construindo o inédito viável da unidade na diversidade, apontando para o que Paulo Freire (1992) chamava a atenção: a única minoria é a dominante. Vemos seringueiros e povos indígenas perceberem-se como povos da floresta, e populaçóes ribeirinhas, atingidas por enchentes, e camponeses a eles se juntarem, numa mesma luta pela terra. Unidade como seres humanos, pois como o mesmo Freire (1987) nos ensina: consciência de classe oprimida dá-se na consciência de ser humano oprimido, como estampado em jornal: "Sem-terra, sem-teto, indígenas e desempregados se mobilizam em todo o país contra as injustiças sociais" (Carrano, 2007).

Nós, latino-americanos, estamos historicamente em um processo desumanizante, ainda em curso, e várias práticas sociais aqui construídas, gestadas, apagadas, negadas estão a ele aliadas - ou contrapostas, pois como nos alerta Freire (1987, p. 30): desumanização, 
Pesquisa e trabalho profissional como espaços e processos de humanização...

"mesmo que um fato concreto na história, não é, porém, destino dado" (grifo do autor).

\section{Do trabalho em comunhão ${ }^{2}$ e da comunidade de trabalho}

A educação dialógica acontece no trabalho conjunto e no intercâmbio em que todos aceitam como valiosas as diferentes contribuiçôes de cada um, embora oriundas de diferentes bases, sejam elas, por exemplo, do conhecimento acadêmico ou do popular. Nesse ser e estar com, para e na comunidade, as pessoas se formam educadoras, participando de processos educativos mais complexos do que a multiplicação estéril de informações a que estão reduzidos muitos programas de educação comunitária (Oliveira \& Silva, 1999).

Por outro lado, na relação opressora da educação bancária, ${ }^{3}$ o elemento básico é a prescrição, ou seja, falar da realidade como algo alheio à experiência existencial das pessoas, onde a sonoridade da palavra e o discurso domesticador dão o tom. Palavra quase sempre acompanhada de uma falsa generosidade, e que nunca a ultrapassa. Palavra alienada, pois reconhece a ignorância apenas no outro. Palavra alienante, pois nega a vocação para a humanização de todos os seres humanos e absolutiza a ignorância do outro, vendo nela a razão da existência do educador. Nessa educação, "o sujeito não se encontra mais no mundo que ajuda a reconstruir; nele, nesse mundo desumanizado, fica retido como objeto de outro sujeito: aliena-se" (Fiori, 1986, p. 7). A contradição educador-educando sequer está posta, pois se trata de relação entre ser e não-ser (Dussel, s/d), entre sujeito e objeto (Fiori, 1986), entre "ser mais" e "ser menos" (Freire, 1987).

A razão de ser da educação popular, da educação libertadora, diz Freire (1987), está no seu impulso inicial conciliador, na superação dessa contradição educador-educando. Na relação dialógica opõe-se a convivência autêntica à gregarização, a criadora à adaptação, atores a espectadores; busca-se ter opções ao invés de seguir prescriçôes (Freire, 1987). Já é notória a seguinte frase desse autor: "ninguém liberta ninguém, ninguém se liberta sozinho, os homens se libertam em comunhão" (idem, ibid., p. 52). Não se justifica numa relação pedagógica que nos aproximemos do outro como "quase coisas", na pretensão de transformá-lo em ser humano, numa educação para eles e não com eles. Não há um $a$ 
posteriori libertador que justifique um meio opressor ou uma visão do outro como objeto, ainda que inicial. Ambos são sujeitos do conhecimento da realidade e de sua recriação.

Uma postura que propicie o diálogo pressupõe a visão do outro como sujeito, a compreensão de que os saberes da população "são elaborados sobre experiência concreta, sobre vivências distintas daquelas do profissional", sendo, portanto, saberes apenas diferentes, mas não inferiores (Valla, 1998, p. 14). Este reconhecimento do outro como sujeito e da ação que ele conduz implica um respeito pelos saberes de experiência.

Defendo a necessidade que temos, educadoras e educadores progressistas, de jamais subestimar ou negar os saberes de experiência feitos. (...) subestimar a sabedoria que resulta necessariamente da experiência sociocultural é, ao mesmo tempo, um erro científico e a expressão inequívoca de uma ideologia elitista (...). Negação do saber popular [é] tão contestável quanto sua mitificação, quanto sua exaltação, de natureza "basista". (Freire, 1992, p. 85)

$\mathrm{Na}$ relação de comunhão, conhecimentos são colocados à disposição e respeitados num processo de conscientização de todos e de ampliação do conhecimento acerca daquela realidade. Impossível, pois, nesta relação, tanto girar sem saída em torno do senso comum, quanto girar em torno do conhecimento sistemático do educador, como expressão inequívoca da realidade que se quer transformar. Conhecer para superar, lançar-se mais além de sua natureza, libertar-se dos limites, localizar-se no mundo, iluminá-lo e percebê-lo, não como espetáculo, mas como obra (Fiori, 1986). "A cultura se faz, pois, num fazer que, reflexivamente, se percebe fazendo: é o saber da cultura" (idem, p. 8), que se constrói nas intersubjetividades, elaborando o mundo em comunhão. "Elaboração que postula, necessariamente, colaboração-participação. Participação que radica na comunicação do saber da cultura: participação no saber, no saber fazer, no fazer que se sabe" (idem, p. 9). Pela comunhão constitui-se uma comunidade de trabalho, na qual pessoas se unem

(...) em torno de objetivos comuns que ultrapassam a ordem pessoal, se situam e se enraízam em compromisso com a construção de uma sociedade justa que garanta iguais direitos e tratamento diverso para diferentes condiçōes, circunstâncias. (Silva \& Araujo-Olivera, 2004, p. 2) 
Pesquisa e trabalho profissional como espaços e processos de humanização...

Nas experiências de constituição de comunidades de trabalho articulam-se e confrontam-se, em processos de interação subjetiva, grupos de origens e classes distintas, grupos que constroem vínculos afetivos e político-ideológicos, grupos compromissados com a construção do sujeito-cidadão (Assis, 2001; Pedrosa, 2001). A dimensão coletiva, criada a partir das condiçóes de vida das pessoas, distingue claramente a educação popular em saúde transformadora desses grupos das propostas alternativas individualizantes da classe média (Valla, 2001).

\section{A convivência metodológica}

Em publicação anterior, Eduardo Stotz e eu apontávamos a necessidade da convivência estar prevista na metodologia de trabalho entre comunidades (Oliveira \& Stotz, 2004), seja este de caráter mais interventivo, seja de pesquisa. Compreender e dialogar exige mais do que uma visita; significa uma vivência próxima, afetiva e comprometida. Muitos aspectos das relações sociais nessas comunidades, suas histórias, desafios e saberes só são percebidos desta forma. Wellington, professor e pesquisador que entrevistei, cita a pesquisa feita por ocasião da epidemia da dengue no final dos anos de 1990, na cidade do Rio de Janeiro. Naquela ocasião, as estatísticas diziam que:

95\% de determinadas comunidades tinham água encanada. Então, quando se (...) foi conversar (...) as pessoas diziam "sim, o cano tem, mas a água não". Então veja, eu tinha uma estatística oficial e quando se foi conversar com as pessoas, você acrescenta outras informações negando, inclusive, o dado oficial. (Oliveira, 2003, p. 105)

É a convivência, com olhar e escuta atentos, que nos leva a compreender a diversidade. Nem a academia, nem os movimentos sociais, as ONGS ou as favelas e, muito menos, as pessoas que atuam nesses espaços têm configuração social homogênea. Na convivência, somos incitados e incitadas a procurar e respeitar as diversas manifestaçóes espirituais, materiais e culturais. No encontro com grupos populares tem-se a fala da população, que é quem sabe da vida que vive, e a fala do técnico, que é um saber também de vida, mas recortado pela técnica, pela ciência, pela escolaridade. A relação com o tempo, com o dinheiro, com o consumo é diferente. ${ }^{4}$ Reconhecer que 
somos diferentes não deveria redundar em posturas inferiorizadoras por parte de quaisquer grupos ou pessoas.

A convivência permitirá perceber o que cotidianamente aflige as pessoas e, assim, repensar trabalhos coletivos e políticas públicas, tornando-os mais condizentes com a concretude do cotidiano. Conviver é mais do que visitar e, não sendo algo que possa ser delegado, requer um envolvimento pessoal de observação, questionamento e diálogo. Somente olho no olho com o outro e, com ele convivendo, é que se pode detectar e compreender posições políticas e informações que nos são fornecidas sobre dada realidade.

Os processos de investigar e de atuar profissionalmente junto a outras comunidades diferentes da minha exigem um afastamento epistemológico, um emergir, para que o conhecimento crítico possa ter lugar e tempo para ser construído. Emersão dialeticamente implicada com a imersão crítica que abordarei mais abaixo (Freire, 1987). Quanto mais mergulhados estamos na realidade que queremos compreender criticamente, mais molhados dela estaremos quando nesse afastamento. Não se trata, a emersão, de um esquecimento ou uma negação de onde me encontro, de mim mesmo/a. A emersão crítica e engajada requer sentir a umidade dos meus condicionantes históricos e sociais, das inquietaçóes que me puseram em movimento, em rebeldia, diz Freire (1999), à postura bancária.

A emersão se dá a cada momento em que faço meu diário de campo, em que garimpo os achados, as falas, as interpretações para melhor compreender a visão de mundo das pessoas com quem trabalho; no diálogo insistente e crítico com a literatura; mas, sobretudo, na compreensão daquela realidade como totalidade histórica, social e econômica. Esta emersão não me exclui do que quero conhecer, como se fosse possível conhecer o mundo sem cruzar, nessa caminhada, consigo próprio. Consciência é um adentramento em si mesmo e uma volta pelo mundo, diz Fiori (1986). Assim, meu diário de campo, por exemplo, falará não apenas do que observei estando entre aquelas pessoas, mas também do que observei em mim, de meus aprendizados, de meus pré-conceitos, numa atenta autoescuta; falará das relações que consigo ou não estabelecer entre os acontecimentos ali ocorridos e outros que, histórica e/ou geograficamente, encontram-se a certa distância daquelas vivências; e, enfim, falará de um reconhecimento do passado na rede em que todas as histórias 
Pesquisa e trabalho profissional como espaços e processos de humanização...

se constituem entre si, como diz Benjamin (1993), iluminando o presente e o passado, acendendo esperanças.

Uma vez feita a emersão crítica como desvelamento de realidades, mundo que se expressa, continuamos no processo de conhecer criticamente e imergimos na realidade, num contínuo movimento de reflexão/ação com a intenção de transformá-la coletivamente. ${ }^{5}$ Reflexão e ação não são momentos separáveis, como tópicos que se seguem passo a passo. E nem a reflexão é própria da emersão e a ação, da imersão, pois, como já dito acima, ambas se implicam dialeticamente. A ação não prescinde da reflexão, nem esta àquela, pois "nem a consciência é reflexo do mundo, nem este é simples projeção daquela” (Fiori, 1986, p. 4). Conscientização é um significar ativo, "um fazer que não termina em produto feito, mas em que o feito é uma contínua manifestação de um fazer que se refaz, continuamente (...). Neste sentido, a expressão do mundo não acontece nem sucede a sua transformação: uma contém a outra; uma ultrapassa a outra e coincidem" (idem, ibid., p. 4).

Superar a contradição educador-educando, vimos atrás, é educar-se em comunhão. Superar essa contradição em nossas pesquisas é poder vivenciar um processo em que o participante é aquele que, ao pesquisar-se, pesquisa; e o pesquisador é aquele que, ao pesquisar, pesquisa-se, num reencontro com sua humanidade. Processos educativos (de pesquisa e de intervenção, incluídos) dialógicos que se dão nesta prática não são um simples trocar de ideias, mas um ato de criação. Para que o diálogo ocorra é necessária uma profunda amorosidade, reconhecer-se como ser inacabado, inconcluso, tendo a humildade de se perceber tão ser humano quanto quaisquer outros. Assim, a afetividade, ao contrário de atrapalhar nossos trabalhos, coloca-se como principal elemento para essa comunhão.

Poderemos ouvir que o rigor das pesquisas fica prejudicado, na medida em que as pessoas passam a participar das investigações em torno de si mesmas, ou ainda que a presença popular nas etapas da pesquisa impede que os achados se apresentem de forma pura. Sobre estas afirmações, junto-me a Brandão (2003) em seus questionamentos sobre a interferência da subjetividade do pesquisador na interpretação dos dados: seria possível evitá-la?. A ciência, diz o autor, fala através de pessoas, que são sujeitos de escolhas e preferências. 


\section{Compromisso social e ético}

Numa história de colonização do pensamento e de formação acadêmica majoritariamente alienada e alienante, encontramos movimentos de contraposição a este modelo: projetos, sobretudo extensionistas populares, que ampliam as possibilidades dos jovens de pensar sua atuação profissional; pesquisas dialógicas/comunicativas, cuja relevância social não está circunscrita apenas à justificativa inicial, mas está presente em seu percurso metodológico e nos resultados; trabalhos no sistema de saúde integrando saber científico e popular, iniciativas de técnicos e de pessoas de movimentos e práticas populares. $^{6}$

Nesses trabalhos o compromisso ético e social é ponto de partida e chegada. Falo de um compromisso com a melhoria das condições de vida e saúde da população brasileira, na busca da equidade, do respeito à vida e da dignidade das pessoas, da valorização do saber e cultura populares, da inclusão e controle sociais e da superação de todas as formas de desigualdade e discriminação. O retorno à comunidade dos ganhos ou resultados desses trabalhos não se dá, exclusivamente, no terreno do compartilhamento de informações, mas também na efetiva contribuição social, que deve ser anunciada na justificativa do trabalho, prevista na metodologia e verificada em seus resultados.

Percebemos que, para que ocorra a participação e se estabeleça a credibilidade dos grupos, é necessário que haja clareza para todos os envolvidos sobre as reais possibilidades de retorno. Às vezes, para se ter a colaboração da população, o retorno é previsto, prometido, mas não é cumprido. Este modo de agir coloca especialmente as pessoas da comunidade, com as quais se fez os contatos, em situação delicada e desgastante. Wellington (in: Oliveira, 2003) ilustra isso com uma pesquisa que foi realizada em Manguinhos (cidade do Rio de Janeiro) para verificar a eficácia de uma nova vacina contra meningite. Previa-se a coleta de sangue de mil crianças, de 1 a 5 anos, que seriam vacinadas no posto de saúde. De um lado, as mães, diante do conhecido sofrimento das crianças nessa situação, não concordavam que seus filhos fossem puncionados, a não ser que o resultado fosse apresentado a elas. Por outro lado, a chefia da pesquisa avaliava que o resultado da viragem sorológica da criança não continha informação relevante para as mães, 
Pesquisa e trabalho profissional como espaços e processos de humanização...

pois apenas os resultados examinados no seu conjunto teriam significado epidemiológico. Tendo isso sido dito às mães, elas insistiram em saber. Diante disso, o chefe de pesquisa concluiu:

\begin{abstract}
"Se as crianças serão sangradas se depois fornecidos os resultados para as mães, então tá bom. A gente vai dar o resultado para elas". Resultado esse que nunca saiu. $\mathrm{O}$ sangue foi todo congelado. Não houve retorno para a população. Quem intermediava essa população de mães era o programa de agentes de saúde da Unidade Sanitária da Escola de Saúde Pública e com isso o programa, como não houve retorno, como nunca saiu esse retorno, o programa de agentes comunitários de saúde começou a se desgastar e terminou acabando. (Oliveira, 2003, p. 116)
\end{abstract}

\title{
Palavras finais
}

Conviver é mergulhar nos processos vivos de educação, saúde, sobrevivência e luta, os quais o(a) pesquisador(a), ou o(a) profissional, se dispõe a compreender. Conviver é conhecer a vida humana sempre em movimento: ora suave, ora abrupto; ora lento, ora vertiginoso; ora leve, ora sufocante; ora harmonioso, ora ensurdecedor. Vidas, vivências, amizades, sabores, cheiros, texturas, sons, palavras, cores, lágrimas e sorrisos tecem uma rede que embala o pesquisador(a), o(a) profissional, integrando-o(a) aos movimentos do viver e redirecionando-lhe o olhar para novas perspectivas, visões do mundo. Assim, pode ele(a) admirar o mundo, com vagar, de modo que o seu trabalho se constitua verdadeiramente como experiência (Larossa-Bondia, 2002).

Ao se realizar trabalhos na busca do diálogo com o outro, tendo o compromisso ético e social como ponto de partida e chegada, aprende-se a convivência e, com ela, a gostar de si e da vida. Aprende-se pessoalmente e profissionalmente e, com isso, ganha-se não só em experiência, mas também com a riqueza do conhecimento construído. Nessa prática social de recriação do mundo, de aproximação de sujeitos, humanizamo-nos para a humanização de todos os envolvidos, que podem então "reencontrar-se no processo como sujeitos de sua própria destinação histórica, autores de sua existência (...) a comunhão pessoal só tem um nome: colaboração no mundo comum” (Fiori, 1986, p. 10).

Recebido em abril de 2008 e aprovado em maio de 2009. 


\section{Notas}

1. Desde 1998, coordeno, juntamente com a professora Petronilha Beatriz Gonçalves e Silva, o Grupo de Pesquisa Práticas Sociais e Processos Educativos, onde investigamos a educação em diversas práticas sociais. Refiro-me à educação que acontece nas relações cotidianas, aquela que requer um olhar atento para sair do campo da naturalização de relações, do imperceptível. Desde 2001, pesquisadores desse Grupo, juntamente com outros, reunem-se na Linha de Pesquisa com o mesmo nome, no Programa de PósGraduação em Educação da UFSCAR. Nela formamos pesquisadores e realizamos pesquisas visando a compreensão desses processos, do ponto de vista dos que dele fazem parte, particularmente, das pessoas marginalizadas e desqualificadas. Preocupamos em nos situar e a nossas investigações no contexto cultural, social e político da América Latina. Em 2000, iniciei minha participação nos debates e trabalhos da Rede de Educação Popular e Saúde, atuando, no momento de publicação deste artigo, como sua coordenadora.

2. Tomamos o sentido de "comunhão" a partir da leitura de Pedagogia do Oprimido, de Paulo Freire (1987). "Comunhão" vai além da mera contraposição ao isolamento e individualismo, apreendendo a "solidariedade dos existires (...). Ninguém pode ser, autenticamente, proibindo que os outros sejam" (p. 75). Nela não há divisão entre a práxis do educador e do educando, sendo que, nessa unidade ("com-um"), não é possível “(...) a manipulação, a sloganização, o 'depósito', a condução, a prescrição (...)" daquele sobre este (p. 123). O outro não é a incidência passiva do meu pensar; assim, o trabalho em comunhão não é um trabalho "sobre o outro", ou "sem" o outro, ou "para" o outro, ou "em torno" do outro (para aí permanecer), mas "com" o outro. Dessa comunhão, indubitavelmente dialógica, se faz a co-laboração.

3. Expressão que se refere a uma postura educacional de depósito de conhecimentos de um no outro (Freire, 1987).

4. Carla, membro de uma ONG que assessora movimentos populares, diz em relação ao tempo: "A gente é capaz de começar a pensar uma reunião, meses antes (...). Da parte dos grupos populares: 'semana que vem já é muito longe, mês que vem então, eu não sei se eu tô vivo", e complementa "Por que tem a fome, tem uma série de coisas. A campanha da fome: 'Quem tem fome, tem pressa'” (Oliveira, 2003, p. 85).

5. Para um aprofundamento de estudos sobre emersão e imersão crítica, sugiro a leitura de Paulo Freire, particularmente, Pedagogia do oprimido.

6. Uma amostra dessas pesquisas e trabalhos pode ser vista nos Anais do III e IV Encontros Nacionais de Educação Popular e Saúde, realizados em 2007 e 2008.

\section{Referências}

ASSIS, M. Uma nova sensibilidade nas práticas de saúde. In: VASCONCELOS, E.M. (Org.). A saúde nas palauras e nos gestos: reflexôes da rede de educação popular e saúde. São Paulo: HUCiTeC, 2001. p. 36-38

BENJAMIM, W. Magia e técnica: arte e política, obras escolhidas. São Paulo: Brasiliense, 1993. 
Pesquisa e trabalho profissional como espaços e processos de humanização...

BRANDÃO, C.R. A pergunta a várias mãos: a experiência da pesquisa no trabalho do educador. São Paulo: Cortez, 2003.

CARRANO, P. Violência: a repressão aumenta no campo. Brasil de Fato, São Paulo, n. 216, p. 1, abr. 2007.

DUSSEL, E.D. Para uma ética da libertação latino-americana III: erótica e pedagógica. São Paulo: Loyola; Piracicaba: UnimeP, [s.d.].

FIORI, E.M. Conscientização e educação. Educação \& Realidade, Porto Alegre, v. 11, n. 1, p. 3-10, 1986.

FREIRE, P. Pedagogia do oprimido. 17. ed. Rio de Janeiro: Paz \& Terra, 1987.

FREIRE, P. Pedagogia da esperança: um reencontro com a pedagogia do oprimido. Rio de Janeiro: Paz \& Terra. 1992.

FREIRE, P. Pedagogia da autonomia: saberes necessários à prática educativa. 13. ed. São Paulo: Paz \& Terra. 1999.

IANNI, O. O labirinto latino-americano. Petrópolis: Vozes, 1993.

LARROSA-BONDÍA, J. Notas sobre a experiência e o saber da experiência. Revista Brasileira de Educação, Rio de Janeiro, n. 19, p. 20-28, 2002.

OLIVEIRA, M.W.; STOTZ, E.N. Perspectivas de diálogo no encontro entre organizações governamentais e instituição acadêmica: o convívio metodológico. In: REUNIÃO ANUAL DA ANPEd, 27., 2004, Caxambú. Anais... "Sociedade, democracia e educação: qual Universidade?”. Caxambú: ANPEd, 2004. (CD-ROM).

OLIVEIRA, M.W.; SILVA, P.B.G. Agentes educacionais em comunidades: processos de interação, integração e educação. Trabalho apresentado na Reunião do Núcleo Educação para a Integração da Associação das Universidades do Grupo Montevidéu. Paraná-Argentina: UnESCO; AUGM; UNER, mar. 1999.

OLIVEIRA, M.W. Processos educativos em trabalhos desenvolvidos entre comunidades: perspectivas de diálogo entre saberes e sujeitos. Rio de Janeiro: Fundação Oswaldo Cruz, 2003. (Relatório de pós-doutorado. Departamento de Endemias "Samuel Pessoa"). 
PEDROSA, J.I.S. Educação popular, saúde, institucionalização: temas para debate. In: VAsconcelos, E.M. (Org.). A saúde nas palavras e nos gestos: reflexões da rede de educação popular e saúde. São Paulo: HUCITEC, 2001. p. 33-35.

SILVA, P.B.G.; ARAUJO-OLIVERA, S.S. Cidadania, ética e diversidade: desafios para a formação em pesquisa. Trabalho apresentado no 6. Encuentro Corredor de las Ideas del Cono Sur "Sociedad civil, democracia e integración”, Montevideo, 2004.

SOUZA, E.S. Educação popular e saúde: cidadania compartilhada. In: VAsConcelos, E.M. (Org.). A saúde nas palavras e nos gestos: reflexões da rede de educação popular e saúde. São Paulo: HUCiTec, 2001. p. 30-32.

VALLA, V.V. Sobre participação popular: uma questão de perspectiva. Cadernos de Saúde Pública, Rio de Janeiro, v. 14, supl. 2, p. 7-18, 1998.

VALLA, V.V. Globalização e saúde no Brasil: a busca da sobrevivência pelas classes populares via questão religiosa. In: VAsConcelos, E.M. (Org.). A saúde nas palavras e nos gestos: reflexões da rede de educação popular e saúde. São Paulo: HUCiTec, 2001. p. 39-62. 